\title{
Total removal of heavy metal from mixed plating rinse wastewater
}

\begin{abstract}
A mixed plating rinse wastewater containing zinc, hexavalent chromium, trivalent chromium, and cyanide with total dissolved solids of $424 \mathrm{mg} / 1$ was treated by a model consisting of a sand filter and ion exchange columns. A strongly acidic cation resin in hydrogen form and a strongly basic anion resin in hydroxide form were used in the columns as cationic and anionic exchangers, respectively. The cationic and anionic exchangers were regenerated by using $2 \%$ $\mathrm{H} 2 \mathrm{SO} 4$ and $5 \% \mathrm{NaOH}$, respectively. A $100 \%$ removal of zinc, total chromium, hexavalent chromium and trivalent chromium was achieved in the studies. Very high removal of total dissolved solids, cyanide and hardness level was achieved at 98.9\%, 99.9\% and 96.5\%, respectively. The conductivity of wastewater was reduced from an average of $358 \mathrm{\varepsilon s} / \mathrm{cm}$ to 5 $\varepsilon s / \mathrm{cm}$. The case study has shown that treatment systems using cationic and anionic resin were able to treat a mixed plating bath effluent to comply with the standard discharge under the Malaysian Environmental Quality (Sewage and Industrial Effluents) Regulation, 1979.
\end{abstract}

Keyword: Removal; Heavy metal; Plating; Rinse wastewater; Ion exchange 